\title{
Detection of Quorum Sensing Signals in Gram-Negative Bacteria by Using Reporter Strain CV026
}

\author{
Ahmad HUMAYAN KABIR ${ }^{1)}$, Anindya GHOSH ROY') \\ Mohammad FIROZ ALAM ${ }^{3}$, Rafiul ISLAM ${ }^{3}$ \\ ${ }^{1)}$ Flinders University, School of Biological Sciences, SA 5042, Australia; abmad.kabir@flinders.edu.au \\ 2) Max Planck Institute for Developmental Biology, D-72076 Tübingen, Germany \\ 3) University of Rajshahi, Department of Botany, Rajshahi 6205, Bangladesh
}

\begin{abstract}
Quorum sensing signals are referred to as acylated homoserine lactones (AHL) that are mainly found in Gram-negative bacteria. It implies the ability of certain bacteria of producing different AHL molecules. The bacteria Pseudomonas aureofaciens and Xenorhabdus nematophila were cultured in Luria-Bertani $\left(\mathrm{LB}_{10}\right)$ media and CV026 was used as a reporter strain to detect the presence of AHLs produced by the cultured bacteria. In this study, the reporter strain has revealed the quorum sensing ability of $P$. aureofaciens and $X$. nematophila by producing the purple pigment violacein in the supply of external AHLs molecules. Thin layer chromatography (TLC) bioassay having four controls was conducted to detect specific AHL molecule supplied by $P$. aureofaciens and $X$. nematophila. The specific AHL molecule was observed to be migrated according to their polarity on the TLC plate.
\end{abstract}

Keywords: quorum sensing, reporter strain, agar-plate based assay, bacterial communication

\section{Introduction}

Communication between bacterial species is done by some diffusible chemical signals, which help them in behavior and function in a group of bacterial population. Bacteria can control and regulate their gene expression by a signaling system from one cell to another cell (Reading and Sperandio, 2006). Quorum sensing is a process by which bacteria regulate the gene expression in response to the variation in cell density in a population (Miller and Bassler, 2001; Fuqua et al., 1994). It is reported in a diverse bacterial population and it mainly enables the communication channel. Many types of signaling molecules have been described in bacteria. The most common signaling molecules found in Gram-negative bacteria are acylated homoserine lactones (AHLs), OHHL (N-3(oxohexanoyl)-L-homoserine lactone) and OHL ( $N$-octanoyl-1-homoserine lactone). Modulation of the physiological processes controlled by AHLs occurs according to cell density and growth phase (Whitehead et al., 2001). AHLs molecules spread out of the cell both into the media and cells that bring equilibrium between the intra and extracellular space (Viana et al., 2009; Steindler and Venturi, 2007). The intercellular level of AHLs increases according to the increase of bacterial cell density until the threshold concentration. In this situation, the AHLs facilitate the induction of quorum sensing genes (Viana et al., 2009).

Quorum sensing is generally found in both Gramnegative bacteria and Gram-positive bacteria (Gram et al., 2002). It is suggested that AHLs were first observed in Vibrio fischeri, a bioluminiscent bacterium (Bassler et al., 1993), which shows the LuxI-LuxR system of quorum sensing. LuxI gene produces a diffusible signal molecule that increases as the cell density increases. After the discovery of AHL-mediated quorum sensing in $V$. fischeri, similar systems involving LuxI and LuxR regulatory proteins have been identified in a wide range of Gram-negative bacteria (Barnard and Salmond, 2005). Reporter gene found in Chromobacterium violaceum produces violacein (purple pigment) that has antibiotic feature against some organisms. Veselova et al. (2003) noticed that violacein is controlled by quorum sensing molecule HHL (N-hexanoyl$\mathrm{L}$-homoserine lactone). C. violaceum 026 (CV026) is a strain that is unable to produce HHL and violacein. But it retains the ability to produce in the presence of external AHLs, which will be determined by the change of color from white to purple in colony. Thin-layer chromatography (TLC) is a technique to separate the signal molecules to determine how many different AHLs are present in tested bacterial samples.

In this study, two Gram-negative bacterial species were used namely, $P$. aureofaciens and $X$. nematophila. $P$. aureofaciens is a free-living bacterium, commonly found in soil and water in addition to the surfaces of plants and animals. $X$. nematophila is a rod-shaped, Gram-negative facultative anaerobic bacterium that lives as a symbiont with nematodes. The aim of this study was to detect and separate 
quorum sensing signals (AHLs) by agar-plate based bioassay.

\section{Materials and methods}

\section{Media and culture preparation}

P. aureofacience, $X$. nematophila and C. violaceum 026 were cultured in one liter of Luria-Bertani $\left(\mathrm{LB}_{10}\right)$ media supplemented with $10 \mathrm{~g}$ bacto-tryptone, $5 \mathrm{~g}$ yeast extract and $10 \mathrm{~g} \mathrm{NaCl}$ at $\mathrm{pH} 7.0$ and then immediately sterilized by autoclaving. Other materials such as tips, Schott bottles and tubes were also autoclaved. $P$. aureofacience and $X$. nematophila were grown on $\mathrm{LB}_{10}$ media and AHLs were extracted using ethyl acetate after two hours interval. The reporter strain CV026 was then used to detect the presence of the AHLs.

\section{Preparation of samples and extraction of supernatant}

The bacteria used in this study were centrifuged at $8000 \mathrm{rpm}$ for 8 minutes and supernatant with AHL was then removed. The bacteria were then transferred to two Schott bottles containing additional media $(50 \mathrm{ml})$ which was placed in a shaker spinning at $200 \mathrm{rpm}$. In every two hours interval, $1 \mathrm{ml}$ of sample was taken from the Schott bottles and the optical density was measured in a spectrophotometer. The samples were diluted by 10 fold dilution, if the OD value was found 2. Subsequently, ethyl acetate was used for AHLs extraction and the samples were transferred into small glass vial and were allowed to evaporate.

\section{Culture of reporter strain and preparation of media}

The reporter bacterial strain CV026 was cultured in $\mathrm{LB}_{10}$ broth media containing kanamycin $(25 \mu \mathrm{g} / \mathrm{ml})$ and was kept for incubation over night on a shaker spinning at $200 \mathrm{rpm}$ at $28^{\circ} \mathrm{C}$. Sterile media and agar plates were prepared and kept at $45^{\circ} \mathrm{C}$.

\section{Agar-plate based biossay}

Agar-plate based bioassay was conducted using the reporter strain and the test strain or extract was spotted on top of the agar. After incubation, the surroundings of the spots were screened for the presence of the reporter violacein.

\section{Inspection of agar plates and preparation of TLC plates}

The AHLs molecules were separated using the thinlayer chromatography, where molecules were separated based on their polarity. Violacein production leading to dark purple pigmentation by the reporter strain was inspected and diameter of spots was measured. Samples from
P. aureofaciens for 8 and 10 hours and $X$. nematophila for 8 hours were taken for TLC plates.

\section{Inspection of TLC plate}

TLC is a technique to separate the signal molecules to determine how many different AHLs a particular sample contains. The TLC plates were observed for the production of violacein zone that used in the agar-plate based bioassay.

\section{Results and discussion}

Value of optical density was taken from $P$. aureofacience and $X$. nematophila for each 2 hours interval up to 10 hours (Fig. 1). The violacein zone produced by bacteria at different time was also measured. It was revealed that CV026 produced violacein in the presence of AHLs molecules from both $P$. aureofacience and $X$. nematophila. AHL production using violacein was also found in several strains of enterobacteriaceae isolated from food (Ravn et al., 2001). Two samples of $P$. aureofaciens and one sample of $X$. nematophila were selected for TLC for determining the AHLs molecules down the track (Fig. 2). It was evident that the optical density of the $P$. aureofaciens and $X$ nematophila increased with time from 0-8 hours, but it suddenly decreased a bit after 10 hours (Fig. 1). CV026 is deficient in the production of AHLs as well as violacein, which was found to produce violacein again in the external supply of AHLs later on. Purple pigment (violacein) resulting $31 \mathrm{~mm}$ and $38 \mathrm{~mm}$ in diameter for 8 and 10 hours respectively, was noticed after applying the AHLs produced from $P$. aureofaciens to the reporter strain (Fig. 1 ). In case of $X$. nematophila, violacein zone was found to be $36 \mathrm{~mm}$ and $34 \mathrm{~mm}$ in diameter extracted from the $8^{\text {th }}$ and $10^{\text {th }}$ hours samples, respectively. It must be noted that the bacterial population was at threshold stage denoted by a high optical density (OD) value at $8^{\text {th }}$ and $10^{\text {th }}$ hour (Fig. 1 ). It is suggested that quorum sensing signals are produced at this threshold stage.

Thin-layer chromatography data demonstrated that the $P$. aureofaciens was corresponded to a AHLs molecule having smaller molecular weight (high polarity) and as a result it travelled a long way on TLC plate (Fig. 2). In all four controls, AHLs having same concentration showed variation of results and it was due to the reason of producing violacein by reporter strain with the supply of specific AHL molecule supplied by $P$. aureofaciens and $X$. nematophila. Detection of AHLs by thin layer chromatography with the $A$. tumefaciens (pZLR4) strain used as a biosensor was reported by several workers (García-Aljaro et al., 2008; Kawaguchi et al., 2008). It can thus be concluded that AHLs molecules were produced by the two tested bacteria ( $P$. aureofaciens and $X$. nematophila) since CV026 can only produce violecein in the presence of external sup- 
74

ply of AHLs molecules. The versatility of CV026 in fa- from this study that the two bacteria have the quorum cilitating the detection of AHL has also been previously sensing activities since CV026 found to be positive for reported (McClean et al., 1997). It can also be revealed AHLs molecules.

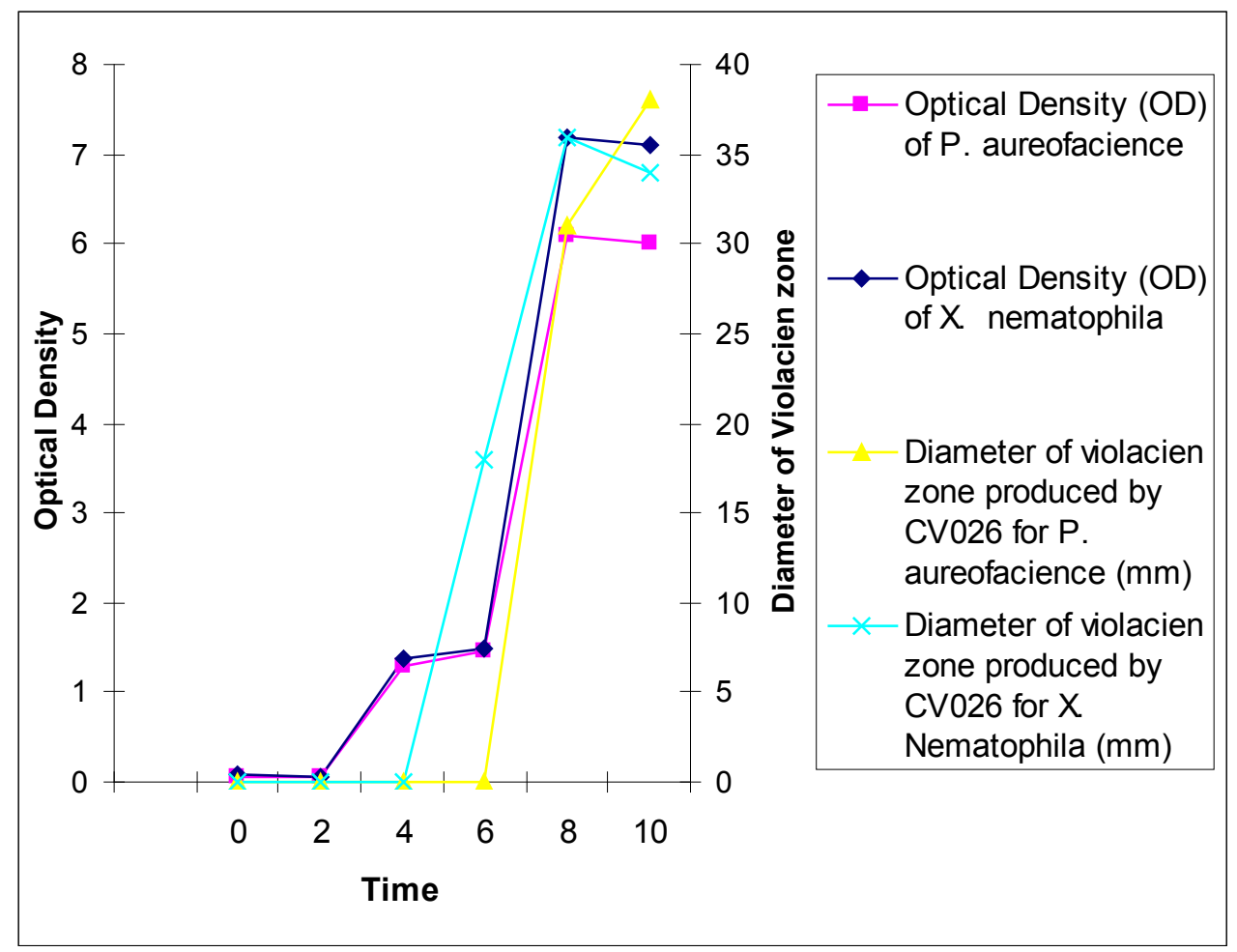

Fig. 1. Values of optical density (OD) of $P$. aureofaciens and $X$. nematophila represented on primary Y-axis, Diameter of violacein zone produced by reporter strain is plotted on secondary Y-axis. Time in hours plotted on $\mathrm{X}$-axis

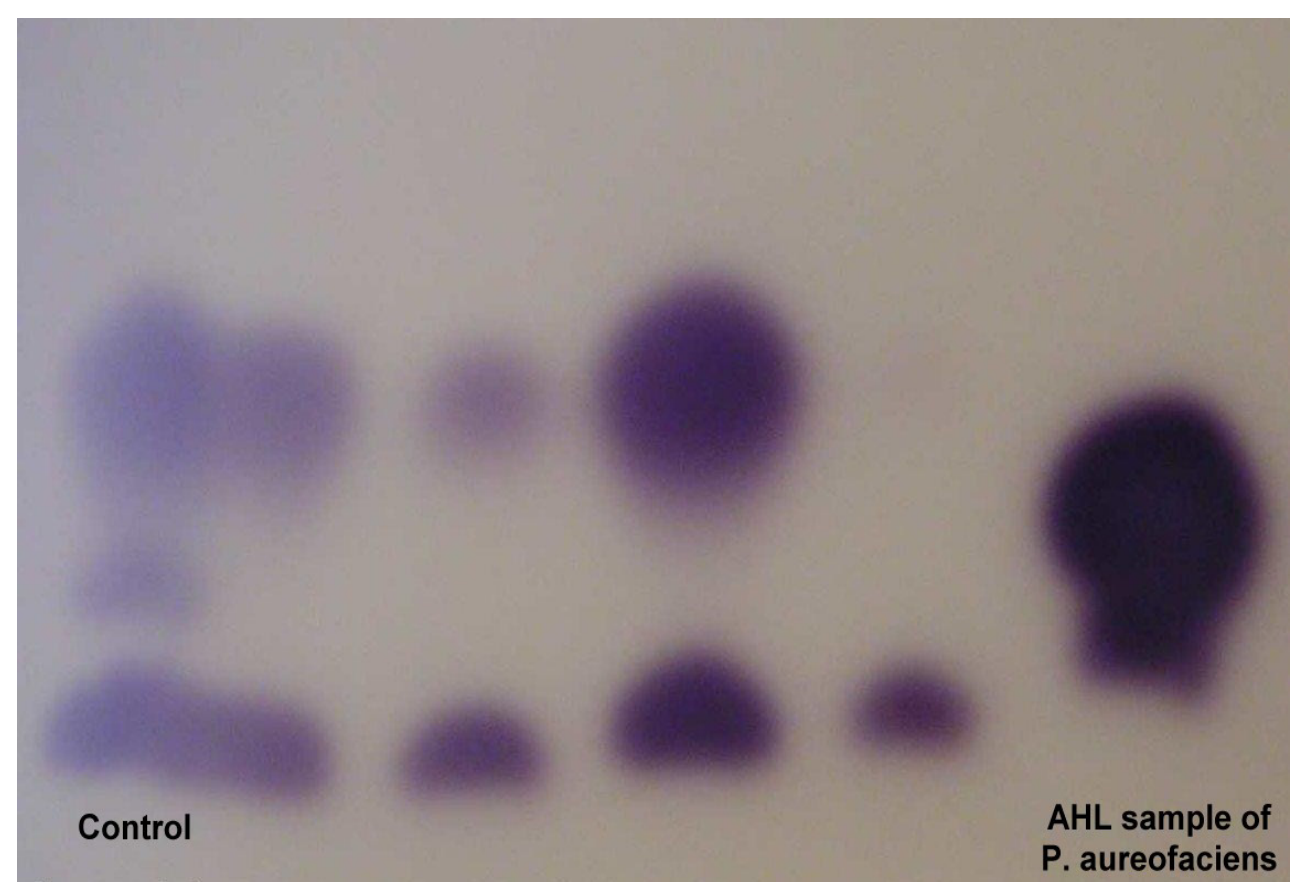

Fig. 2. Detection of AHL molecule by thin layer chromatography. Control - Mixture of OHHL, HHL, OHL and BHL 


\section{Conclusions}

Isolating AHLs from Gram-negative bacteria and to detect these quorum sensing molecules by agar-plate based bioassay using a reporter strain is a crucial issue. It was observed that AHLs molecules were produced by both $P$. aureofaciens and $X$. nematophila in TLC plates. It pinpoints the activity of CV026 as a reporter strain to detect quorum sensing molecules. TLC proved to be an efficient method for detecting quorum sensing molecules in $P$. aureofacience.

\section{References}

Barnard, A. M. L. and G. P. C. Salmond (2005). Quorum Sensing: The Complexities of Chemical Communication between Bacteria. Complexus 2:87-101.

Bassler, B. L., M. Wright, R. E. Showalter and M. R. Silverman (1993). Intercellular signalling in Vibrio harveyi: sequence and function of genes regulating expression of luminescence. Molecular Microbiology 9:773-786.

Cámara, M., A. Hardman, P. Williams and D. Milton (2002). Quorum sensing in Vibrio cholerae. Nature Genetics 32:217218.

Fuqua, W. C., S. C. Winans and E. P. Greenberg (1994). Quorum sensing in bacteria: the LuxR-LuxI family of cell density-responsive transcriptional regulators. Journal of Bacteriology 176:269-275.

García-Aljaro, C., L. Eberl, K. Riedel and A. R. Blanch (2008). Detection of quorum-sensing-related molecules in Vibrio scophthalmi. BMC Microbiology 8:138.

Gram, L., H. Grossart, A. Schlingloff and T. Kiørboe (2002). Possible quorum Sensing in Marine Snow Bacteria: Production of Acylated Homoserine Lactones by Roseobacter Strains Isolated from Marine Snow. Applied and Environmental Microbiology 8 (68):4111-4116.
Kawaguchi, T., Y. P. Chen, R. S. Norman and A. W. Decho (2008). Rapid Screening of Quorum-Sensing Signal N-Acyl Homoserine Lactones by an in vitro Cell-Free Assay. Applied and Environmental Microbiology 74(12):3667-3671.

McClean, K. H., M. K. Winson, L. Fish, A. Taylor, S. R. Chhabra, M. Camara, M. Daykin, S. Swift, B. W. Bycroft, G. S. A. B. Stewart and P. Williams (1997). Quorum sensing and Chrornobacteriurn violaceurn : exploitation of violacein production and inhibition for the detection of $\mathrm{N}$-acyl homoserine lactones. Microbiology 143:3703-3711.

Miller, M. B. and B. L. Bassler (2001). Quorum sensing in bacteria. Annual Review of Microbiology 55:165-99.

Ravn, L., A. B. Christensenb, S. Molinb, M. Givskovb and L. Gram (2001). Methods for detecting acylated homoserine lactones produced by Gram-negative bacteria and their application in studies of AHL-production kinetics. Journal of Microbiological Methods 44(3):239-251.

Reading, N. C. and V. Sperandio (2006). Quorum sensing: the many languages of bacteria. FEMS Microbiology Letters. 254(1):1-11.

Steindler, L. and V. Venturi (2007). Detection of quorumsensingN -acyl homoserine lactone signal molecules by bacterial biosensors. FEMS Microbiology Letters 266:1-9.

Veselova, M., M.Kholmeckaya,S. Klein, E. Voronina, V.Lipasova, A. Metlitskaya, A. Mayatskaya, E. Lebanok, I. Khmel and L. Chernin (2003). Production of N-Acylhomserine lactone signal molecules by gram-negative soil-borne and plantassociated bacteria. Folia Microbiology 48(6):794-798.

Viana, E. S., M. E. M. Campos, A. R. Ponce, H. C. Mantovani, and M. C. D. Vanetti (2009). Biofilm formation and acyl homoserine lactone production in Hafnia alvei isolated from raw milk. Biological Research 42:427-436.

Whitehead, N. A., A. M. Barnard, H. Slater, N. J. Simpson and G. P. Salmond (2001). Quorum-sensing in Gram-negative bacteria. FEMS Microbiology Review 25(4):365-404. 